\title{
Can patients with moderate to severe acute respiratory failure from COPD be treated safely with noninvasive mechanical ventilation on the ward?
}

\author{
This article was published in the following Dove Press journal: \\ International Journal of COPD \\ 31 May 2016 \\ Number of times this article has been viewed
}

\author{
Murat Yalcinsoy' \\ Cuneyt Salturk ${ }^{2}$ \\ Selahattin Oztas ${ }^{2}$ \\ Sinem Gungor ${ }^{2}$ \\ Ipek Ozmen ${ }^{2}$ \\ Feyyaz Kabadayi \\ Aysem Askim Oztim² \\ Emine Aksoy ${ }^{2}$ \\ Nalan Adıguzel ${ }^{2}$ \\ Ozlem Oruc ${ }^{2}$ \\ Zuhal Karakurt ${ }^{2}$ \\ 'Department of Pulmonary Medicine, \\ Inonu University Medical Faculty, \\ Turgut Ozal Medical Center, Malatya, \\ ${ }^{2}$ Department of Pulmonary Medicine, \\ Sureyyapașa Chest Diseases and \\ Thoracic Surgery Training and \\ Research Hospital, Istanbul, Turkey
}

Correspondence: Murat Yalcinsoy Department of Pulmonary Medicine, Inonu University Medical Faculty, Turgut Ozal Medical Center, Elazig Yolu 15 km, Malatya 44069, Turkey

Tel +905325692130

Fax +90 216 42I 4II0

Emailmrtyalcinsoy@yahoo.com
Purpose: Noninvasive mechanical ventilation (NIMV) usage outside of intensive care unit is not recommended in patients with COPD for severe acute respiratory failure (ARF). We assessed the factors associated with failure of NIMV in patients with ARF and severe acidosis admitted to the emergency department and followed on respiratory ward.

Patients and methods: This is a retrospective observational cohort study conducted in a tertiary teaching hospital specialized in chest diseases and thoracic surgery between June 1, 2013 and May 31, 2014. COPD patients who were admitted to our emergency department due to ARF were included. Patients were grouped according to the severity of acidosis into two groups: group $1(\mathrm{pH}=7.20-7.25)$ and group $2(\mathrm{pH}=7.26-7.30)$.

Results: Group 1 included 59 patients (mean age: $70 \pm 10$ years, 30.5\% female) and group 2 included 171 patients (mean age: $67 \pm 11$ years, $28.7 \%$ female). On multivariable analysis, partial arterial oxygen pressure to the inspired fractionated oxygen $\left(\mathrm{PaO}_{2} / \mathrm{FiO}_{2}\right)$ ratio $<200$, delta $\mathrm{pH}$ value $<0.30$, and $\mathrm{pH}$ value $<7.31$ on control arterial blood gas after NIMV in the emergency room and peak $\mathrm{C}$-reactive protein were found to be the risk factors for NIMV failure in COPD patients with ARF in the ward.

Conclusion: NIMV is effective not only in mild respiratory failure but also with severe forms of COPD patients presenting with severe exacerbation. The determination of the failure criteria of NIMV and the expertise of the team is critical for treatment success.

Keywords: noninvasive mechanical ventilation, COPD, acute respiratory failure, exacerbation, mortality

\section{Introduction}

Noninvasive mechanical ventilation (NIMV) is a gold standard intervention for acute respiratory failure (ARF) in patients with acute exacerbation of COPD. ${ }^{1}$ With advances in technology and experience, NIMV is more applicable outside of the intensive care unit (ICU) for these COPD patients. ${ }^{2}$ Psychological and economic conditions alike and the limited number of ICU beds conduce NIMV application outside the ICU. ${ }^{3}$ Many studies have reported the use of NIMV in general wards for COPD patients and other diseases. ${ }^{2,45}$

NIMV application outside the ICU remains controversial, especially considering the risk in patients with $\mathrm{pH}<7.30$ on the arterial blood gas (ABG) analysis for COPD. ${ }^{6}$ There are only a few studies published about NIMV application in these risky patients in the ward. ${ }^{7,8}$ The concept of safety has been poorly notified. Furthermore, NIMV can have a very high failure rate and a delay in ICU transfer or tracheal intubation should 
be avoided. ${ }^{2}$ The amount of data about safety and efficacy of NIMV applied outside the ICU is limited. However, due to shortage of ICU beds, NIMV can be initiated outside the ICU for COPD patients with very severe respiratory acidosis.

The aim of this article was to define our "real-life" retrospective analysis surrounding the use of NIMV for COPD patients who were hospitalized after admission to the emergency unit with very severe acidosis. In this study, we evaluated the relationship between the severity of ARF, according to the $\mathrm{pH}$ value, and NIMV failure in the COPD patients followed up at the pulmonary ward. Furthermore, we also defined the differences of long-term mortality in patients according to the discharge place and the $\mathrm{pH}$ value on admission.

\section{Patients and methods}

\section{Study design, setting, and population}

The study was designed as a retrospective observational cohort study in a tertiary teaching hospital for chest diseases and thoracic surgery center between June 1, 2013 and May 31, 2014. The study was approved by the local ethics committee of Kartal Lutfi Kirdar Teaching and Research Hospital, Istanbul, Turkey (89513307/1009/316). Ethical approval was obtained in accordance with the Declaration of Helsinki. Due to the retrospective nature of this study, we did not obtain patients' consent for our study; however, during hospital procedure, all treatment and medication were done after obtaining informed consent of the patients.

\section{Patients}

We included patients with previously diagnosed COPD who had been admitted to our emergency department (ED) due to ARF. ${ }^{9}$ The previous diagnosis of COPD was established by a pulmonary physician who evaluated airflow obstruction on spirometry, ie, forced expiratory volume in 1 second $\left(\mathrm{FEV}_{1}\right)$ of $70 \%$ predicted or less, and an $\mathrm{FEV}_{1}$ and forced vital capacity $(\mathrm{FVC})$ ratio $\left(\mathrm{FEV}_{1} / \mathrm{FVC}\right)$ of $70 \%$ or less. ${ }^{1}$ Spirometry test data were not recorded from the patients' charts.

Patients were excluded on the basis of the following criteria: 1) presence of metabolic acidosis, 2) presence of malignancy, 3) pH outside of the desired range, 4) not admitted to the ward (ICU, discharged from the emergency room), or 5) died prior to transfer from the ER (Figure 1).

The study center is the Chest Diseases and Thoracic Surgery Teaching Hospital with large beds $(n=605)$. The ED was operated 24 hours by one chest specialist physician with support from two pulmonology residents, and the nurse:patient ratio was 1:4. Portable monitoring was available with continuous oximetry to monitor heart rate and arterial blood pressure. At the ICU setting, the intensivist/pulmonologist was available 7/24 hours. In the ward setting, all patients received NIMV in the respiratory ward staffed by nurses who were experienced in the application of NIMV, with a nurse:patient ratio of $1: 8$ during the day shift and 1:11 during the night shift. All ward staff nurses were provided training in NIMV at regular intervals by intensivists in our center.

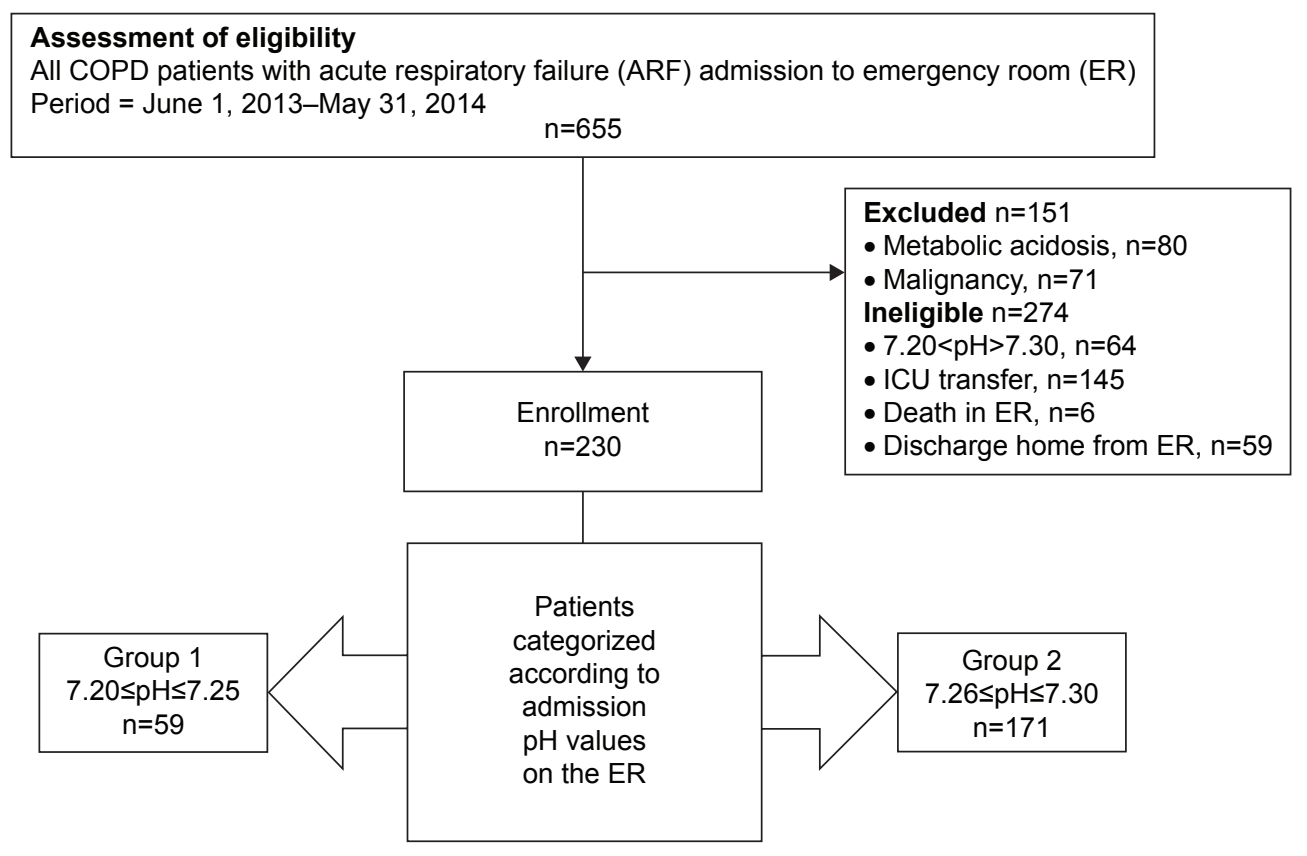

Figure I Consort diagram showing patient enrollment.

Abbreviation: ICU, intensive care unit. 
One chest specialist and one assistant were available on duty for the ward patients. If the patient's condition deteriorated, the doctor on duty was approached to receive an opinion. The ABG values of patients with NIMV were also controlled by the duty doctor at regular intervals. The decision to intubate the patients was taken by the chest specialist.

\section{Bronchodilator and anti-inflammatory treatment at the emergency room and on the ward}

A short-acting $\beta_{2}$ agonist (salbutamol, $100 \mu \mathrm{g}$ per puff) and ipratropium bromide $(100 \mu \mathrm{g} / 20 \mu \mathrm{g}$ per puff) were given every 2-4 hours (4-10 puffs) via a metered dose inhaler chamber (Aerovent, Altech ${ }^{\circledR}$; Altera Firm, Izmir, Turkey) when the patients were under NIMV. A nebular form of salbutamol ( $2.5 \mathrm{mg} / 2.5 \mathrm{~mL}$ per nebule) was given every 15 minutes for 4 hours, or ipratropium bromide/salbutamol $(0.5 \mathrm{mg} / 3.01 \mathrm{mg} /$ $2.5 \mathrm{~mL}$ per nebule) was given every $2-4$ hours. Long-acting $\beta 2$ agonists were not used in the COPD patients with ARF in the ward. Intravenous methylprednisolone (40-60 mg) was given one to two times daily and steroid dose was tapered gradually and discontinued over 7-10 days. Methylxanthines (theophylline and aminophylline) were given $10 \mathrm{mg} / \mathrm{kg}$ daily, with a maximum of $300 \mathrm{mg}$ daily. All patients received oxygen for COPD, as well as medication to treat the underlying cause of ICU admission or ARF and comorbidities, such as antibiotics and antiarrhythmia or anticoagulant therapies. ${ }^{1}$

The ABG sample is immediately obtained and the necessary medical therapy is initiated. NIMV is started if appropriate according to the ABG analysis results. ABG control is performed within 2 hours after NIMV application. According to this control result, the options (follow-up at the ICU, ward, or discharged home) are reviewed. Only patients who were admitted to the emergency room with respiratory acidosis and followed up at the ward were evaluated in this study (Figure 2).

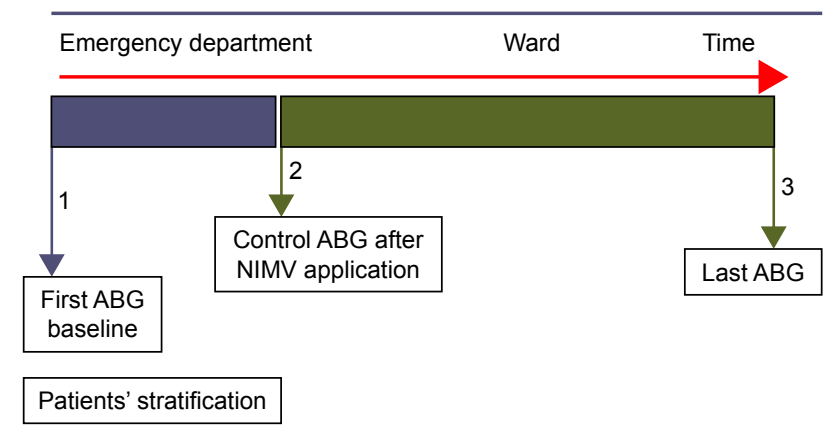

Figure 2 Data recording times of arterial blood gases.

Abbreviations: ABG, arterial blood gas; NIMV, noninvasive mechanical ventilation.

\section{Data source}

The data were gathered retrospectively from a passwordprotected database.

\section{Outcomes}

The primary outcome was NIMV failure (transfer to ICU or death). The secondary outcome was the length of hospital stay. Long-term mortality was also considered.

\section{Primary exposure}

Patients were grouped according to the $\mathrm{pH}$ values: group 1 $(\mathrm{pH}=7.20-7.25)$ and group $2(\mathrm{pH}=7.26-7.30)$ (Figure 3$)$.

\section{Additional covariates}

The demographics were recorded, and ABG assessments were performed at the time of admission to the ED and on admission to the ward. The reasons for ARF, such as pneumonia, right heart failure from pulmonary embolism, and comorbidities including diabetes mellitus, arrhythmia (ie, atrial fibrillation), hypertension, congestive heart failure, coronary artery disease, and malignancy, were also registered. History of smoking, use of long-term oxygen therapy (LTOT), and long-term NIMV were recorded. The serum peak C-reactive protein (CRP) levels, the white blood cell count, hemoglobin, hematocrit, platelet, and biochemical parameters (glucose, creatinine, BUN, AST, ALT, sodium, potassium, albumin) at the ED and on admission to the ward were recorded. Application of NIMV, inspiratory and expiratory pressure values, type of mask, duration of hospital stay (days), and mortality rates were recorded.

\section{Definitions}

Hypoxic ARF is defined as the ratio of the partial arterial oxygen pressure to the inspired fractionated oxygen $\left(\mathrm{PaO}_{2} /\right.$ $\left.\mathrm{FiO}_{2}\right)<300$ and the partial arterial carbon dioxide pressure $\left(\mathrm{PaCO}_{2}\right)$ of $<45 \mathrm{mmHg}$. Hypercapnic/hypoxemic ARF is defined as $\mathrm{PaCO}_{2}>45 \mathrm{mmHg}$ and $\mathrm{PaO}_{2} / \mathrm{FiO}_{2}<300$, and hypercapnic ARF as $\mathrm{PaCO}_{2}>45 \mathrm{mmHg}$ and $\mathrm{PaO}_{2} /$ $\mathrm{FiO}_{2}>300$. $^{6,10} \mathrm{COPD}$ exacerbation due to an infectious origin is defined by the presence of all three Anthonisen's

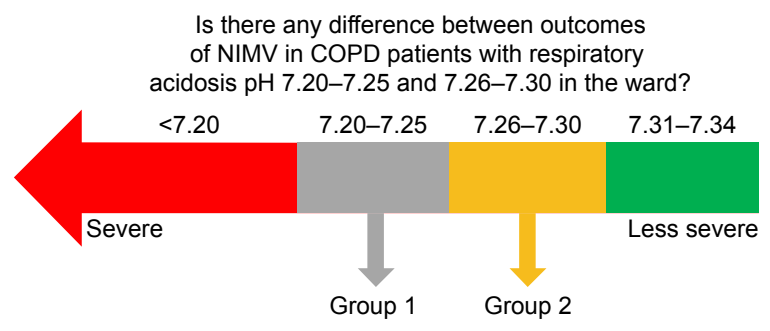

Figure 3 Definition of respiratory acidosis. Abbreviation: NIMV, noninvasive mechanical ventilation. 
criteria: worsening of dyspnea, increased volume of pulmonary secretions (endotracheal, sputum), and increased purulence of respiratory secretions. ${ }^{11}$

\section{Criteria for ICU admission}

Unstable patients' hemodynamics (mean arterial pressure $<65 \mathrm{mmHg}$ ), clinical deterioration (respiratory rate $>40 / \mathrm{min}$, use of accessory muscles of respiration, dependency on NIV with inability to remain off NIV for longer than two hours, moods get agitated, or incompatible mask), requirements for close monitorization of cardiac and mental function.

\section{Experienced ward}

In our center, all physicians, nurses, and other health care staff were familiar with NIMV. Residents were well trained in respiratory ICU for management of NIMV. Ward staff were experienced as ICU staff. ICU nurses changed their work location from ICU to ward and vice versa. Each year one or two NIMV practical and theoretical courses for nurses and doctors were conducted by the ICU teaching team. For this reason, we used the term "experienced ward".

\section{Mechanical ventilation}

Initially, NIMV was applied to all the COPD patients with hypercapnic respiratory failure, except when absolutely contraindicated. NIMV contraindications were defined as 1) absolute respiratory arrest and inability to fit the mask, and 2) relative, medically unstable (hypotensive shock, uncontrolled cardiac ischemia or arrhythmia, or uncontrolled copious upper gastrointestinal bleeding), agitation, uncooperativeness, inability to protect airway, impaired swallowing, excessive secretions not managed by clearance techniques, multiple (two or more) organ failure, and recent upper airway or upper gastrointestinal surgery. ${ }^{12}$

NIMV was provided routinely at the ED with a oronasal mask to all patients, and expiratory positive airway pressure was initially set at the level of $5 \mathrm{~cm} \mathrm{H}_{2} \mathrm{O}$ and was increased by $1-2 \mathrm{~cm} \mathrm{H}_{2} \mathrm{O}$ if needed to achieve an oxygen arterial pressure $\left(\mathrm{PaO}_{2}\right)$ of $60 \mathrm{mmHg}$ or lower or an $\mathrm{SpO}_{2}$ of $90 \%$ or lower. Inspiratory positive airway pressure was increased to $20 \mathrm{~cm}$ $\mathrm{H}_{2} \mathrm{O}$ with increases of $2-3 \mathrm{~cm} \mathrm{H}_{2} \mathrm{O}$ to obtain a tidal volume of 6-8 $\mathrm{mL} / \mathrm{kg}$ and a respiratory rate of 30 breaths/min or lower. NIMV was applied intermittently for periods of 1-4 hours, and ABG samples were obtained again in 2 hours. The definitions of NIMV failure in hypercapnic patients were no $\mathrm{pH}$ improvement, no change or a rise in breathing frequency after 1-2 hours, and lack of cooperation. For hypoxic COPD patients, failure was considered as none or a minimal rise in $\mathrm{PaO}_{2} / \mathrm{FiO}_{2}$ after $1-2$ hours $(<200) .{ }^{12}$

\section{Statistical analysis}

A descriptive analysis was performed to investigate the patient demographics and data. The groups were compared with the Mann-Whitney $U$-tests and the Student's $t$-tests for the nonparametric and parametric continuous variables, respectively. The chi-square test was used for the dichotomous variables. The median with interquartile range was employed for the nonparametric continuous variables, and the mean \pm standard deviation was used for the parametric continuous variables. Counts and percentages were used when applicable. The Kaplan-Meier survival analysis was carried out to predict the long-term mortality in the patient groups after ICU discharge and according to the place where the patient was discharged from (ICU vs ward). A $P$-value $<0.05$ was accepted as statistically significant. The SPSS-20 portable package program was used to perform the statistical analyses (SPSS v20.0; IBM Corporation, Armonk, NY, USA).

\section{Results}

The patients' characteristics according to the study groups have been summarized in Table 1. Both groups had similar age, sex, smoking history, comorbid diseases, and reasons of ARF on admission to ER.

The baseline laboratory values have been demonstrated in Table 2. Both groups had similar complete blood count (CBC) and biochemistry results, except for the serum creatinine levels which were significantly higher in the severe acidotic group $(P<0.035)$. The baseline $\mathrm{ABG}$ results have also been summarized in Table 2 . The oxygenation levels were similar among the groups, and $\mathrm{pH}$ was significantly lower, and the $\mathrm{PaCO}_{2}$ was significantly higher than those of the moderate acidotic group.

The control ABG values after NIMV treatment in the emergency room were similar in both the study groups (Table 3). The patients' last $\mathrm{ABG}$ and $\mathrm{CBC}$ results before being discharged home from the ward were also similar in both the groups. The outcomes of the patients are summarized in Table 3. The length of hospital stay, the rate of patients sent to the ICU, and the mortality rates were similar in both the groups. The delta $\mathrm{pH}$ values after NIMV application in the emergency room were significantly higher in the severe acidotic group $(P<0.001)$. NIMV intolerance was observed in $3.05 \%$ of the cases (seven patients). NIMV was ceased in $10.4 \%$ of the cases (24 patients) when their respiratory acidosis resolved.

The risk factors for NIMV failure at the ward were analyzed with the binary logistic regression test (Table 4). $\mathrm{A} \mathrm{PaO}_{2} /$ $\mathrm{FiO}_{2}$ ratio $<200$ in the emergency room, a delta $\mathrm{pH}$ value $<0.30$, and a $\mathrm{pH}$ value $<7.31$ on control ABG after NIMV and 
Table I Characteristics of COPD patients with ARF admitted to emergency room

\begin{tabular}{|c|c|c|c|}
\hline Variable & $\begin{array}{l}7.20 \leq p H \leq 7.25 \\
(n=59)\end{array}$ & $\begin{array}{l}7.26 \leq \mathrm{pH} \leq 7.30 \\
(\mathrm{n}=|7|)\end{array}$ & $P$-value \\
\hline Age, mean \pm SD (years) & $70 \pm 10$ & $67 \pm 11$ & 0.12 \\
\hline Female (\%) & 30.5 & 28.7 & 0.79 \\
\hline BMI, median (IQR) $\left(\mathrm{kg} / \mathrm{m}^{2}\right)$ & $25(23-30)$ & $24(20.2-30)$ & 0.09 \\
\hline \multicolumn{4}{|l|}{ Smoking history (\%) } \\
\hline Current & 25.4 & 29.4 & 0.64 \\
\hline Ex-smoker & 45.8 & 45.3 & 0.80 \\
\hline Systolic arterial pressure $(\mathrm{mmHg})$, mean $\pm \mathrm{SD}$ & $120 \pm 23.3$ & $130 \pm 12.4$ & 0.33 \\
\hline Diastolic arterial pressure $(\mathrm{mmHg})$, mean $\pm \mathrm{SD}$ & $75 \pm 12.4$ & $70 \pm 12.2$ & 0.47 \\
\hline Biomass $(\%)$ & 28.8 & 25.3 & 0.33 \\
\hline COPD duration, mean \pm SD (years) & $\mathrm{II} \pm 8$ & $12 \pm 9$ & 0.75 \\
\hline LTOT (\%) & 71.2 & 78.4 & 0.27 \\
\hline NIMV at home (\%) & 49.2 & 46.8 & 0.75 \\
\hline \multicolumn{4}{|l|}{ Comorbidities (\%) } \\
\hline Diabetes mellitus & 32.2 & 23.4 & 0.19 \\
\hline Arrhythmia & 6.8 & 5.3 & 0.74 \\
\hline Hypertension & 57.6 & 49.7 & 0.29 \\
\hline Cardiac disease & 55.9 & 48.5 & 0.33 \\
\hline \multicolumn{4}{|l|}{ Reasons of ARF (\%) } \\
\hline Pneumonia & 18.6 & 15.2 & 0.13 \\
\hline COPD exacerbation due to infection & 78.0 & 82.5 & 0.45 \\
\hline Congestive right heart failure & 3.4 & 2.3 & 0.66 \\
\hline
\end{tabular}

Notes: Data with respect to BMI value was missing for 14 patients in group I and for 42 patients in group 2 . COPD duration data was missing for one patient in group 2. Abbreviations: ARF, acute respiratory failure; SD, standard deviation; BMI, body mass index; IQR, interquartile range; LTOT, long-term oxygen therapy; NIMV, noninvasive mechanical ventilation.

peak CRP were found to be the risk factors for NIMV failure in COPD patients with ARF in the ward (Table 5).

After hospital discharge, 216 patients were followed up for 15 months and the Kaplan-Meier survival analysis was performed. Both groups showed similar survival curves $(P>0.23)$ (Figure 4).
Patients who were referred to the ICU due to NIMV failure were also followed up. The comparison of their survival rates with patients discharged from the ward has been demonstrated in Figure 5. Patients discharged from the ICU demonstrated significantly shorter survival rate than those discharged from the ward $(P<0.004)$.

Table 2 The comparison baseline results of COPD patients with acute respiratory failure at emergency room

\begin{tabular}{|c|c|c|c|}
\hline Variable & $\begin{array}{l}7.20 \leq p H \leq 7.25 \\
(n=59)\end{array}$ & $\begin{array}{l}7.26 \leq \mathrm{pH} \leq 7.30 \\
(\mathrm{n}=|7| \mathrm{I})\end{array}$ & $P$-value \\
\hline \multicolumn{4}{|c|}{ Baseline complete blood count, mean \pm SD } \\
\hline White blood cell $\left(\times 10^{9} / \mathrm{L}\right)$ & $10,442 \pm 5,205$ & $10,854 \pm 4,977$ & 0.59 \\
\hline Hemoglobin $(g / d L)$ & $13.7 \pm 2.3$ & $13.6 \pm 2.1$ & 1.26 \\
\hline Hematocrit (\%) & $42.6 \pm 6.6$ & $42 \pm 6.9$ & 0.57 \\
\hline Platelet count $\left(\times 10^{9} / \mathrm{L}\right)$ & $242 \pm 98$ & $264 \pm 109$ & 0.17 \\
\hline \multicolumn{4}{|l|}{ Baseline blood biochemistry } \\
\hline Glucose $(\mathrm{mmol} / \mathrm{L})$ mean $\pm \mathrm{SD}$ & $168 \pm 66$ & $153 \pm 60$ & 0.12 \\
\hline Blood urea nitrogen, mean \pm SD (mmol/L) & $27.3 \pm 20.6$ & $21.7 \pm 12.6$ & 0.051 \\
\hline Creatinine, median (IQR) (mg/dL) & $0.95(0.73-1.26)$ & $0.83(0.72-1.03)$ & 0.035 \\
\hline Sodium, mean \pm SD $(\mathrm{mmol} / \mathrm{L})$ & $139 \pm 4$ & $138 \pm 5$ & 0.32 \\
\hline Potassium, mean $\pm \mathrm{SD}(\mathrm{mmol} / \mathrm{L})$ & $5 \pm 1$ & $5 \pm 1$ & 0.34 \\
\hline Albumin, mean $\pm S D(g / d L)$ & $3.3 \pm 0.4$ & $3.3 \pm 0.5$ & 0.07 \\
\hline \multicolumn{4}{|l|}{ Baseline arterial blood gases } \\
\hline $\mathrm{pH}$, mean $\pm \mathrm{SD}$ & $7.23 \pm 0.02$ & $7.28 \pm 0.01$ & 0.001 \\
\hline $\mathrm{PaCO}_{2}$, mean $\pm \mathrm{SD}(\mathrm{mmHg})$ & $78.09 \pm 16.47$ & $68.28 \pm 10.14$ & 0.001 \\
\hline $\mathrm{PaO}_{2} / \mathrm{FiO}_{2}$, median (IQR) & $345(225-483)$ & $315(230-443)$ & 0.52 \\
\hline
\end{tabular}

Abbreviations: SD, standard deviation; IQR, interquartile range; $\mathrm{PaCO}_{2}$, partial arterial blood carbon dioxide pressure; $\mathrm{PaO}_{2} / \mathrm{FiO}{ }_{2}$, partial arterial blood oxygen pressure over inspired oxygen fractionation. 
Table 3 The outcome of the COPD patients with acute respiratory failure admitted to the ward from emergency room

\begin{tabular}{|c|c|c|c|}
\hline \multirow[t]{2}{*}{ Variable } & \multirow{2}{*}{$\frac{7.20 \leq p H \leq 7.25}{(n=59)}$} & \multirow{2}{*}{$\frac{7.26 \leq \mathrm{pH} \leq 7.30}{(\mathrm{n}=|7|)}$} & \multirow[t]{2}{*}{$P$-value } \\
\hline & & & \\
\hline \multicolumn{4}{|l|}{ Control ABG after NIMV } \\
\hline $\mathrm{pH}$, mean $\pm \mathrm{SD}$ & $7.33 \pm 0.05$ & $7.34 \pm 0.04$ & 0.14 \\
\hline $\mathrm{PaCO}_{2}$, mean $\pm \mathrm{SD}(\mathrm{mmHg})$ & $58.68 \pm \mid 3.87$ & $58.45 \pm 11.26$ & 0.91 \\
\hline $\mathrm{PaO}_{2} / \mathrm{FiO}_{2}$, median (IQR) & $156(123-189)$ & $161(133-211)$ & 0.12 \\
\hline ABG on the last day of ward & $\mathrm{n}=\mathbf{5 5}$ & $n=168$ & \\
\hline $\mathrm{pH}$, mean $\pm \mathrm{SD}$ & $7.38 \pm 0.06$ & $7.38 \pm 0.07$ & 0.84 \\
\hline $\mathrm{PaCO}_{2}$, mean $\pm \mathrm{SD}(\mathrm{mmHg})$ & $57.9 \pm 14.9$ & $59.2 \pm 12.9$ & 0.53 \\
\hline $\mathrm{PaO}_{2} / \mathrm{FiO}_{2}, \operatorname{median}(\mathrm{IQR})$ & $166(139-212)$ & $169(\mid 40-217)$ & 0.78 \\
\hline \multicolumn{4}{|c|}{ Complete blood count on the last day of ward } \\
\hline White blood cell, mean $\pm S D\left(\times 10^{9} / L\right)$ & $9,356 \pm 3,737$ & $9,946 \pm 7,578$ & 0.59 \\
\hline Hematocrit, mean \pm SD (\%) & $40 \pm 6.5$ & $39.5 \pm 6.5$ & 0.63 \\
\hline Platelet, mean $\pm \mathrm{SD}\left(\times 10^{9} / \mathrm{L}\right)$ & $221 \pm 88$ & $252 \pm 104$ & 0.056 \\
\hline Peak C-reactive protein, median (IQR) (mg/L) & $21(7.8-54.5)$ & $21.8(6.0-57.4)$ & 0.73 \\
\hline \multicolumn{4}{|l|}{ Outcome of ward } \\
\hline Length of ward stay, median (IQR) (days) & $7(5-8)$ & $6(5-9)$ & 0.43 \\
\hline Referred to ICU, n (\%) & $9(15.3)$ & $26(15.3)$ & 0.99 \\
\hline Hospital mortality, n (\%) & $4(6.8)$ & $4(2.3)$ & 0.11 \\
\hline Delta $\mathrm{pH}$ (control-baseline), mean $\pm \mathrm{SD}$ & $0.11 \pm 0.05$ & $0.06 \pm 0.04$ & 0.001 \\
\hline
\end{tabular}

Table 4 The comparison of $A B G$ and blood samples according to the outcome of the patients at the ward

\begin{tabular}{|c|c|c|c|}
\hline Variable & $\begin{array}{l}\text { NIMV success } \\
(n=193)\end{array}$ & $\begin{array}{l}\text { NIMV failure* } \\
(n=37)\end{array}$ & $P$-value \\
\hline Age, mean \pm SD (years) & $65.86 \pm 13.17$ & $68.38 \pm 9.69$ & 0.18 \\
\hline Female (\%) & 29 & 29.7 & 0.93 \\
\hline BMI, median (IQR) (kg/m²) & $25(22-30)$ & $24(20-28)$ & 0.28 \\
\hline \multicolumn{4}{|l|}{ Reasons of ARF (\%) } \\
\hline Pneumonia & 16.1 & 16.2 & 0.98 \\
\hline COPD exacerbation due to infection & 81.3 & 81.1 & 0.97 \\
\hline Congestive right heart failure & 2.6 & 2.7 & 0.97 \\
\hline \multicolumn{4}{|l|}{ Baseline complete blood count, mean \pm SD } \\
\hline White blood cell $\left(\times 10^{9} / \mathrm{L}\right)$ & $10,826.3 \pm 5,180.2$ & $10,343.7 \pm 4,183.8$ & 0.59 \\
\hline Hematocrit (\%) & $42.09 \pm 6.82$ & $42.60 \pm 6.74$ & 0.68 \\
\hline Platelet count $\left(\times 10^{9} / \mathrm{L}\right)$ & $259.7 \pm 107.02$ & $251.5 \pm 105.4$ & 0.67 \\
\hline \multicolumn{4}{|l|}{ Baseline blood biochemistry } \\
\hline Blood urea nitrogen, mean \pm SD (mmol/L) & $22.34 \pm 14.72$ & $27.14 \pm 17.10$ & 0.08 \\
\hline Creatinine, median (IQR) (mg/dL) & $0.85(0.73-1.1)$ & $0.83(0.7-1.27)$ & 0.81 \\
\hline Albumin, mean $\pm S D(g / d L)$ & $3.3 \pm 0.5$ & $3.2 \pm 0.47$ & 0.33 \\
\hline Peak C-reactive protein (mg/dL), median (IQR) & $20.4(6-52.4)$ & $35.2(15.2-64.9)$ & 0.73 \\
\hline \multicolumn{4}{|l|}{ Baseline arterial blood gases } \\
\hline $\mathrm{pH}$, mean $\pm \mathrm{SD}$ & $7.27 \pm 0.027$ & $7.26 \pm 0.03$ & 0.27 \\
\hline $\mathrm{PaCO}_{2}$, mean $\pm \mathrm{SD}(\mathrm{mmHg})$ & $69.64 \pm 12.05$ & $76.80 \pm 14.89$ & 0.002 \\
\hline $\mathrm{PaO}_{2} / \mathrm{FiO}_{2}<200, \mathrm{n}(\%)$ & $25(13)$ & $13(35.1)$ & 0.001 \\
\hline \multicolumn{4}{|l|}{ Control ABG after NIMV } \\
\hline $\mathrm{pH}$, mean $\pm \mathrm{SD}$ & $7.35 \pm 0.04$ & $7.31 \pm 0.04$ & 0.001 \\
\hline $\mathrm{PaCO}_{2}$, mean $\pm \mathrm{SD}(\mathrm{mmHg})$ & $56.99 \pm 11.72$ & $66.46 \pm 9.90$ & 0.001 \\
\hline $\mathrm{PaO}_{2} / \mathrm{FiO}_{2}<200, \mathrm{n}(\%)$ & $144(74.6)$ & $24(64.9)$ & 0.22 \\
\hline Delta $\mathrm{pH} \leq 0.3$ (control-baseline ABG), $\mathrm{n}$ (\%) & $33(17.1)$ & $15(40.5)$ & 0.001 \\
\hline $\mathrm{pH} \leq 7.3 \mathrm{I}$ at control $\mathrm{ABG}, \mathrm{n}(\%)$ & $28(14.5)$ & $14(37.8)$ & 0.001 \\
\hline
\end{tabular}

Note: *Patients passing away at the ward or sent to ICU.

Abbreviations: ABG, arterial blood gas; NIMV, noninvasive mechanical ventilation; SD, standard deviation; ARF, acute respiratory failure; BMI, body mass index; IQR, interquartile range; $\mathrm{PaCO}_{2}$, partial arterial blood carbon dioxide pressure; $\mathrm{PaO}_{2} / \mathrm{FiO}_{2}$, partial arterial blood oxygen pressure over inspired oxygen fractionation; ICU, intensive care unit. 
Table 5 Binary logistic regression of the risk predictors for NIMV failure (sent to ICU or death) in COPD patients with ARF

\begin{tabular}{|c|c|c|c|}
\hline \multirow[t]{2}{*}{ Predictors } & \multirow[t]{2}{*}{ Odds ratio } & $95 \%$ confidence interval & \multirow[t]{2}{*}{$P$-value } \\
\hline & & Lower-Upper & \\
\hline $\mathrm{pH}<7.3 \mathrm{I}$ on control $\mathrm{ABG}$ after NIMV in ER & 2.84 & $1.09-7.39$ & 0.032 \\
\hline Delta $\mathrm{pH}<0.30$ between baseline and control & 1.60 & $0.59-4.35$ & 0.36 \\
\hline Peak C-reactive protein & 1.02 & $1.01-1.00$ & 0.016 \\
\hline $\mathrm{PaO}_{2} / \mathrm{FiO}_{2}$ ratio $<200$ on control $A B G$ after NIMV & 0.66 & $0.29-1.53$ & 0.34 \\
\hline $\mathrm{PaO}_{2} / \mathrm{FiO}_{2}$ ratio $<200$ on baseline $\mathrm{ABG}$ at the $\mathrm{ER}$ & 3.09 & $1.28-7.44$ & 0.012 \\
\hline
\end{tabular}

Abbreviations: $A B G$, arterial blood gas; $\mathrm{NIMV}$, noninvasive mechanical ventilation; $\mathrm{ER}$, emergency room; ARF, acute respiratory failure; $\mathrm{PaO} / / \mathrm{FiO}_{2}$, partial arterial blood oxygen pressure over inspired oxygen fractionation; ICU, intensive care unit.

\section{Discussion}

The present study showed that COPD patients with severe acidosis admitted to the ED with ARF and treated with NIMV, regardless of the severity of acidosis, may be followed up in the inpatient ward if their $\mathrm{pH}$ values were $>7.31$ in the first 2-hour control, whereas those with $\mathrm{pH}$ values of $<7.31$ should be followed up in the ICU.

The optimal application site of NIMV is still a debate. In a prospective study carried out by Paus-Jenssen et al in Canada, NIMV was shown to have been initiated most commonly in the emergency unit. ${ }^{13}$ In the questionnaire survey carried out by Burns et al, including many centers in Canada and the US, a similar distribution to Paus-Jenssen et al's results was found. ${ }^{4}$ Schettino et al found in their prospective study, where they collected the data of 449 patients treated with NIMV in a center for a year, that in $1 / 5$ of the cases, the NIMV was commenced in the emergency unit;

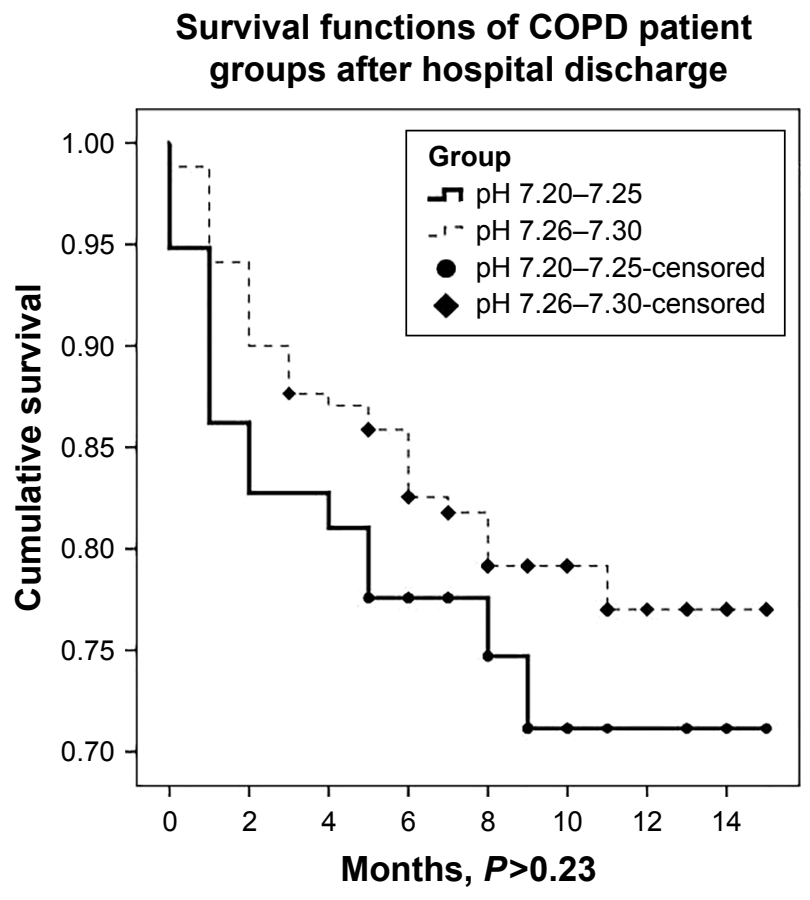

Figure 4 Long-term mortality of COPD patient groups according to their $\mathrm{pH}$ values on admission to the hospital and after discharge from the hospital. in approximately half of them, in the ICU; and in $1 / 3$, in the inpatient wards. ${ }^{14}$ Interestingly, patients who were managed only in the emergency unit had the best results with a $22.6 \%$ rate of intubation and a $7.5 \%$ rate of mortality. In patients who were managed only in the ICU, the intubation rate was $49.4 \%$, and the mortality rate was $28.4 \%$. In patients who were followed up only in the inpatient wards, the intubation rate was $27.3 \%$, and the mortality rate was $14.9 \%$. Schettino et al contributed these results to the occurrence of different comorbidities at different stages of severity. ${ }^{14}$ In our study, patients for whom NIMV had been commenced in the ED were included. In contrast to the other studies, because our hospital is a reference branch hospital, most of our patients were suffering from COPD with exacerbations, and they were evaluated by pulmonary disease specialists, and again, the indication of NIMV, the management of NIMV, and the decision of requirement for ICU were made by pulmonary

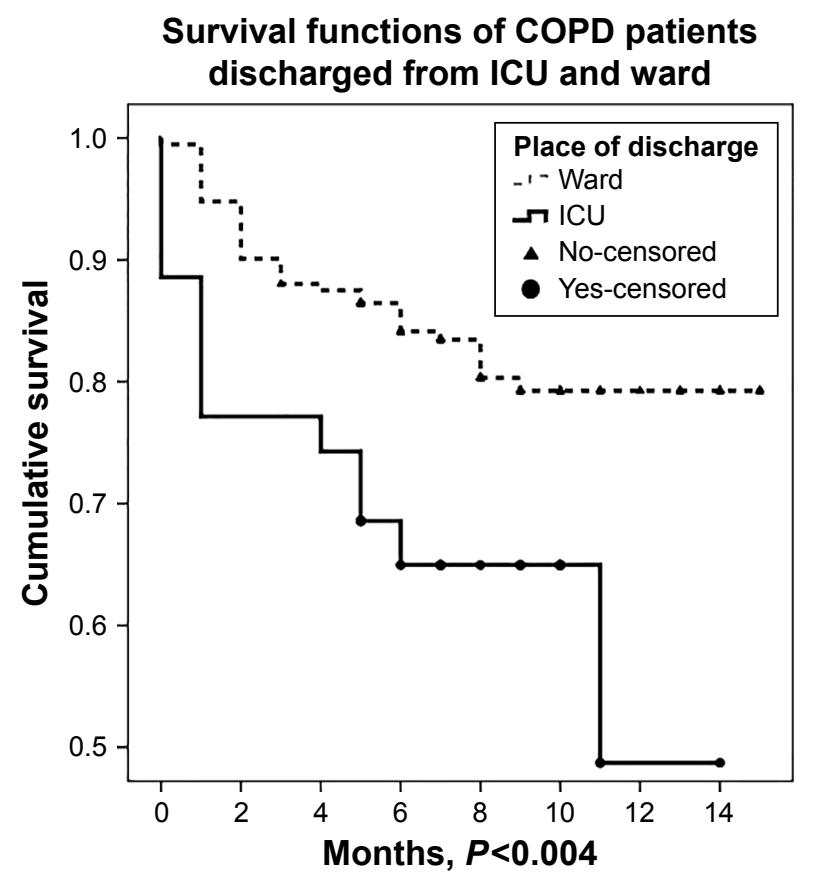

Figure 5 I2-month mortality of COPD patients groups according to the discharge place.

Abbreviation: ICU, intensive care unit. 
disease specialists. Khalid et al reported that the application of NIMV by the Medical Emergency Team was safe. ${ }^{15}$ The high rates of NIMV success in our study also show that NIMV application by experienced staff is safe in selected patients who present with exacerbation of COPD.

The patients with acute hypercapnic COPD were divided into two groups according to a random $\mathrm{pH}$ value of 7.25. Reference to this value was made according to the two published guidelines and according to a previous study suggesting that patients with acute COPD and a $\mathrm{pH}$ value $<7.25$ have a significantly greater mortality compared to patients with a $\mathrm{pH}$ value $>7.25 .^{6,10,16}$ In the present study, on the contrary, the mortality rate was similar in both $\mathrm{pH}$ groups. These studies showed no differences between the two groups in terms of body mass index (BMI), age, frequency of prior use of LTOT, history of smoking, biomass exposure, COPD time, and comorbidity. ${ }^{6,10,16}$ However, the severe acidotic group seemed to have a higher creatinine level than the mild acidotic group, suggesting a more acute presentation. Some studies have emphasized that the low $\mathrm{pH}$ level at the time of application is an indicator of failure of NIMV, and some studies have reported that a $\mathrm{pH}$ value $<7.25$ could be an indicator for intubation and mechanical ventilation. ${ }^{17-19}$ In addition, there are also studies reporting that the change in $\mathrm{pH}$ value is an indicator of success. ${ }^{20}$ However, there is a higher number of studies reporting that the best indicator of success in NIMV is the response in the first 2 hours. ${ }^{21}$ Our study supports that the best indicator is change in $\mathrm{pH}$ value after $2 \mathrm{~h}$ NIMV. Data from a multicenter study carried out in British respiratory general wards indicated that NIMV was probably successful if the $\mathrm{pH}$ and/or the $\mathrm{PaCO}_{2}$ improved after $1-4$ hours. ${ }^{22}$ Crummy et al found a high success rate of NIMV in the study they performed with a total of 36 COPD patients with severe and moderate acidosis. ${ }^{8}$ They reported that with an hour of NIMV application, they observed a significant improvement in the $\mathrm{pH}$ level, and that these patients may be followed up outside of the ICU by experienced staff. ${ }^{8}$ Poponick et al, in a study including COPD patients with congestive heart failure who presented with ARF, reported that the decision for intubation and mechanical ventilation should be made after NIMV follow-up, and that the most important parameters are $\mathrm{pH}$ and $\mathrm{PaCO}_{2}{ }^{23}$ In our study, we had better responses, as in other groups, in patients with severe acidosis after NIMV follow-up. Furthermore, the change in $\mathrm{pH}$ was found to be an independent risk factor for the failure, consistent with other studies. Our study showed that in both groups, approximately half of the patients using NIMV in their homes, presence of concomitant cardiac disease may contribute to the high success of NIMV. Furthermore, the relatively high creatinine levels in the severe acidosis group, without any statistical significance, may have resulted in more favorable response to NIMV in the severe acidosis group.

The only study that gives only one threshold value for $\mathrm{pH}$ level is the one by Merlani et al. ${ }^{24}$ They reported the failure criteria as $\mathrm{pH} \leq 7.35$ and respiratory rate $\geq 20 \mathrm{~min}^{-1}$ after 1 hour of NIMV application in their retrospective study where they evaluated 104 patients with ARF presenting to the emergency room, and they also reported that their patient population was heterogeneous and did not include a sufficient number of subjects for the subgroup analysis. ${ }^{24}$ In Confalonieri et al's prospective cohort study, where they treated $\sim 800$ COPD patients, who were treated with NIMV, they determined four factors that they evaluated at the time of admission and after 2 hours, which they combined in a chart. In the chart which contains Acute Physiology and Chronic Health Evaluation (APACHE) II score, $\mathrm{pH}$, respiratory rate, and Glasgow coma score, the most determining factor after 2 hours of NIMV was found to be $\mathrm{pH}$; the riskiest group was found to be patients with $\mathrm{pH}$ value $<7.25$ at the time of admission and after 2 hours of NIMV, and the lowest failure rate was found to be in the group with $\mathrm{pH}$ value $>7.30$ and APACHE II score $\geq 29$. In a prospective cohort study, including nearly 800 COPD patients treated with NIMV, Confalonieri et al identified four factors - APACHE II score, $\mathrm{pH}$, respiratory rate, and Glasgow coma score - which when combined in a chart demonstrated a good predictive value at the baseline. These factors demonstrated an even better predictive value after 2 hours of NIMV application. If all four factors were favorable, the chance of success was 97\%, whereas if all were unfavorable, failure was a virtual certainty (99\%). ${ }^{10}$ The present study showed that the most important indicator of the success of NIMV in COPD patients with severe acidosis was the $\mathrm{pH}$ level being $>7.31$ after 2 hours of NIMV application.

Hospital mortality in COPD attacks shows a high rate of variability according to the patient population and the unit in which the patients are followed up. In COPD attack, the shortterm cumulative incidence of all deaths in hospital mortality is $3.6 \%$, ranging from $1.8 \%$ to $20.4 \% .^{25-28}$ The cumulative incidence of long-term mortality is $31 \%$, ranging from $18.8 \%$ to $45.4 \%{ }^{27,29-32}$ Up to $53 \%$ of the mortality rate has been reported in ARF patients followed up by mechanical ventilation in the ICU, and an $8 \%$ reduction rate was observed in patients using NIMV. ${ }^{33}$ Quintana et al also found results consistent with ours in their multicenter study in which they investigated the mortality of patients presenting to the hospital with COPD attack. According to their analysis of referral $\mathrm{pH}$ levels of the patients, in which they took pH 7.26 as the basis value, they showed that the application $\mathrm{pH}$ level did not have an effect on 
mortality $(4.4 \%$ vs $2.7 \%, P=0.32) .{ }^{34}$ Our study is consistent with the literature with regard to mortality rates, with low mortality rates found in patients with severe acidosis. This may be explained by the fact that our hospital is a referral hospital, resulting in a homogeneous patient population, and the staff is more experienced. Our study showed that long-term mortality rate was higher in patients who were discharged from ICU than in patients discharged from the ward. This implies that although close follow-up is important for patients requiring NIMV, it is more important for patients who are admitted to ICU due to NIMV failure in the ward.

Confalonieri et al showed no change in the mortality rate with a reduction in the intubation rates as a result of NIMV application in the patient group with heterogeneous ARF and pneumonia. ${ }^{35}$ Phua et al in a study on patients with ARF from COPD or from reasons other than COPD, where they performed NIMV, investigated the failure criteria and found that NIMV was found to be successful in patients without COPD in the presence of pneumonia, but in patients with COPD, pneumonia had no effect. ${ }^{36}$ Studies related to the role of CRP, which is used as an inflammatory marker in the COPD attack, are inconsistent. Some studies and reviews compared CRP and the other markers and found that CRP was ineffective in determining the COPD exacerbation, hospitalization, treatment response, or mortality. ${ }^{37,38}$ Unlike these studies, however, CRP has been found to be a good indicator to show negative results (hospital death, NIMV failure, etc). ${ }^{39-41}$ Moreover, in our study, the presence of pneumonia was ineffective in demonstrating the success of NIMV, whereas the high CRP level was found to be an independent factor. The homogeneity of the patient groups may have had an effect on this result.

Our study has a few limitations. First, due to the retrospective nature of the study, some data were missing. However, our results can still give valuable information. The Glasgow coma scale and the APACHE II score, which are used to determine the severity of the attack, could not be calculated due to the absence of data. Our study presents real-life experience, and these two parameters are not routinely calculated in the emergency room or ward. The infectious etiology has not been investigated and no data is available on this variable. Majority of the COPD exacerbations do not require any microbiological investigation. In addition, because this was a single-center study, the results may be better or worse for similar patients in different centers. Our results cannot be generalized for others with different conditions.

\section{Conclusion}

This observational study enlightens the factors effective on COPD patients presenting with moderate $(7.25<\mathrm{pH} \leq 7.30)$ and severe acidosis $(\mathrm{pH} \leq 7.25)$ and treated with NIMV in the real-life setting. Selected patients may be followed up with NIMV safely in experienced wards instead of close follow-up as in the ICUs. If there is no contraindication, in patients with severe acidosis, the clinical decision should be made with NIMV follow-up. Patients must be closely followed for the first 2 hours. If there is no complication for NIMV usage, most important indicator of the success of NIMV in COPD patients with severe acidosis is the $\mathrm{pH}$ level being $>7.31$ after 2 hours of NIMV application. The ward staff who apply and follow-up NIMV also has to be experienced. The determination of the failure criteria of NIMV with the expertise of the team increases the treatment success in COPD patients presenting with severe exacerbation. Advances in technology will enable us to treat patients with more severe respiratory acidosis outside the ICU.

\section{Acknowledgment}

The authors acknowledge and thank the American Thoracic Society's Methods in Epidemiologic, Clinical and Operations Research (MECOR) Program.

\section{Disclosure}

The authors report no conflicts of interest in this work.

\section{References}

1. Global Strategy for Diagnosis, Management, and Prevention of COPD Global Initiative for Chronic Obstructive Lung Disease; updated 2012. Available from: http://www.goldcopd.org/uploads/users/files/GOLD_ Report_2011_Feb21.pdf. Accessed October 8, 2012.

2. Cabrini L, Antonelli M, Savoia G, Landriscina M. Non-invasive ventilation outside of the intensive care unit: an Italian survey. Minerva Anestesiol. 2011;77(3):313-322.

3. Elliott MW. Noninvasive ventilation in chronic ventilatory failure due to chronic obstructive pulmonary disease. Eur Respir J. 2002;20(3): 511-514.

4. Burns KEA, Sinuff T, Adhikari NKJ, et al. Bilevel noninvasive positive pressure ventilation for acute respiratory failure: survey of Ontario practice. Crit Care Med. 2005;33(7):1477-1483.

5. Ciledag A, Kaya A, Akdogan BB, et al. Early use of noninvasive mechanical ventilation in patients with acute hypercapnic respiratory failure in a respiratory ward: a prospective study. Arch Bronconeumol. 2010;46(10):538-542.

6. Baudouin S, Blumenthal S, Cooper B, et al. Non-invasive ventilation in acute respiratory failure - British thoracic society standards of care committee. Thorax. 2002;57(3):192-211.

7. Mclaughlin KM, Murray IM, Thain G, Currie GP. Ward-based noninvasive ventilation for hypercapnic exacerbations of COPD: a 'real-life' perspective. QJM. 2010;103(7):505-510.

8. Crummy F, Buchan C, Miller B, Toghill J, Naughton MT. The use of noninvasive mechanical ventilation in COPD with severe hypercapnic acidosis. Resp Med. 2007;101(1):53-61.

9. Meduri GU, Turner RE, Abou-Shala N, Wunderink R, Tolley E. Noninvasive positive pressure ventilation via face mask. First-line intervention in patients with acute hypercapnic and hypoxemic respiratory failure. Chest. 1996;109(1):179-193. 
10. Confalonieri M, Garuti G, Cattaruzza MS, et al. A chart of failure risk for noninvasive ventilation in patients with COPD exacerbation. Eur Respir J. 2005;25(2):348-355.

11. Anthonisen NR, Manfreda J, Warren CP, Hershfield ES, Harding GK, Nelson NA. Antibiotic therapy in exacerbations of chronic obstructive pulmonary disease. Ann Intern Med. 1987;106(2):196-204.

12. Nava S, Hill N. Non-invasive ventilation in acute respiratory failure. Lancet. 2009;374(9685):250-259.

13. Paus-Jenssen ES, Reid JK, Cockcroft DW, Laframboise K, Ward HA. The use of noninvasive ventilation in acute respiratory failure at a tertiary care center. Chest. 2004;126(1):165-172.

14. Schettino G, Altobelli N, Kacmarek RM. Noninvasive positive-pressure ventilation in acute respiratory failure outside clinical trials: experience at the Massachusetts General Hospital. Crit Care Med. 2008; 36(2):441-447.

15. Khalid I, Sherbini N, Qushmaq I, et al. Outcomes of patients treated with noninvasive ventilation by a medical emergency team on the wards. Resp Care. 2014;59(2):186-192.

16. Jeffrey AA, Warren PM, Flenley DC. Acute hypercapnic respiratoryfailure in patients with chronic obstructive lung-disease - risk-factors and use of guidelines for management. Thorax. 1992;47(1):34-40.

17. Conti G, Antonelli M, Navalesi P, et al. Noninvasive vs. conventional mechanical ventilation in patients with chronic obstructive disease after failure of medical treatment in the ward: a randomized trial. Intens Care Med. 2002;28(12):1701-1707.

18. Moretti M, Cilione C, Tampieri A, Fracchia C, Marchioni A, Nava S. Incidence and causes of non-invasive mechanical ventilation failure after initial success. Thorax. 2000;55(10):819-825.

19. Titlestad IL, Lassen AT, Vestbo J. Long-term survival for COPD patients receiving noninvasive ventilation for acute respiratory failure. Int J Chronic Obstr. 2013;8:215-219.

20. Antón A, Güell R, Gómez J, et al. Predicting the result of noninvasive ventilation in severe acute exacerbations of patients with chronic airflow limitation. Chest. 2000;117(3):828-833.

21. Garpestad E, Brennan J, Hill NS. Noninvasive ventilation for critical care. Chest. 2007;132(2):711-720.

22. Plant PK, Owen JL, Elliott MW. Non-invasive ventilation in acute exacerbations of chronic obstructive pulmonary disease: long term survival and predictors of in-hospital outcome. Thorax. 2001;56(9):708-712.

23. Poponick JM, Renston JP, Bennett RP, Emerman CL. Use of a ventilatory support system (BiPAP) for acute respiratory failure in the emergency department. Chest. 1999;116(1):166-171.

24. Merlani PG, Pasquina P, Granier JM, Treggiari M, Rutschmann O, Ricou B. Factors associated with failure of noninvasive positive pressure ventilation in the emergency department. Acad Emerg Med. 2005;12(12):1206-1215.

25. Chang CL, Sullivan GD, Karalus NC, Mills GD, Mclachlan JD, Hancox RJ. Predicting early mortality in acute exacerbation of chronic obstructive pulmonary disease using the CURB65 score. Respirology. 2011;16(1):146-151.

26. Roberts CM, Lowe D, Bucknall CE, Ryland I, Kelly Y, Pearson MG. Clinical audit indicators of outcome following admission to hospital with acute exacerbation of chronic obstructive pulmonary disease. Thorax. 2002;57(2):137-141.
27. Singanayagam A, Schembri S, Chalmers JD. Predictors of mortality in hospitalized adults with acute exacerbation of chronic obstructive pulmonary disease. Ann Am Thorac Soc. 2013;10(2):81-89.

28. Tabak YP, Sun XW, Johannes RS, Gupta V, Shorr AF. Mortality and need for mechanical ventilation in acute exacerbations of chronic obstructive pulmonary disease development and validation of a simple risk score. Arch Intern Med. 2009;169(17):1595-1602.

29. Almagro P, Calbo E, de Echaguen AO, et al. Mortality after hospitalization for COPD. Chest. 2002;121(5):1441-1448.

30. Groenewegen KH, Schols AMWJ, Wouters EFM. Mortality and mortality-related factors after hospitalization for acute exacerbation of COPD. Chest. 2003;124(2):459-467.

31. Gudmundsson G, Gislason T, Lindberg E, et al. Mortality in COPD patients discharged from hospital: the role of treatment and co-morbidity. Resp Res. 2006; 7:109.

32. Ranieri P, Bianchetti A, Margiotta A, Virgillo A, Clini EM, Trabucchi M. Predictors of 6-month mortality in elderly patients with mild chronic obstructive pulmonary disease discharged from a medical ward after acute nonacidotic exacerbation. J Am Geriatr Soc. 2008;56(5): 909-913.

33. Ucgun I, Metintas M, Moral H, Alatas F, Yildirim H, Erginel S. Predictors of hospital outcome and intubation in COPD patients admitted to the respiratory ICU for acute hypercapnic respiratory failure. Resp Med. 2006;100(1):66-74.

34. Quintana JM, Esteban C, Unzurrunzaga A, et al. Predictive score for mortality in patients with COPD exacerbations attending hospital emergency departments. BMC Med. 2014;12:66.

35. Confalonieri M, Potena A, Carbone G, Della Porta R, Tolley EA, Meduri GU. Acute respiratory failure in patients with severe community-acquired pneumonia - a prospective randomized evaluation of noninvasive ventilation. Am J Resp Crit Care. 1999;160(5):1585-1591.

36. Phua J, Kong K, Lee KH, Shen L, Lim TK. Noninvasive ventilation in hypercapnic acute respiratory failure due to chronic obstructive pulmonary disease vs. other conditions: effectiveness and predictors of failure. Intens Care Med. 2005;31(4):533-539.

37. Antonescu-Turcua AL, Tomic R. C-reactive protein and copeptin: prognostic predictors in chronic obstructive pulmonary disease exacerbations. Curr Opin Pulm Med. 2009;15(2):120-125.

38. Stolz D, Christ-Crain M, Morgenthaler NG, et al. Copeptin, C-reactive protein, and procalcitonin as prognostic biomarkers in acute exacerbation of COPD. Chest. 2007;131(4):1058-1067.

39. Tofan F, Rahimi-Rad MH, Rasmi Y, Rahimirad S. High sensitive C-reactive protein for prediction of adverse outcome in acute exacerbation of chronic obstructive pulmonary disease. Pneumologia. 2012;61(3):160-162.

40. Karadeniz G, Polat G, Senol G, Buyuksirin M. C-reactive protein measurements as a marker of the severity of chronic obstructive pulmonary disease exacerbations. Inflammation. 2013;36(4):948-953.

41. Ruiz-González A, Lacasta D, Ibarz M, Martínez-Alonso M, Falguera M, Porcel JM. C-reactive protein and other predictors of poor outcome in patients hospitalized with exacerbations of chronic obstructive pulmonary disease. Respirology. 2008;13(7):1028-1033.
International Journal of COPD

\section{Publish your work in this journal}

The International Journal of COPD is an international, peer-reviewed journal of therapeutics and pharmacology focusing on concise rapid reporting of clinical studies and reviews in COPD. Special focus is given to the pathophysiological processes underlying the disease, intervention programs, patient focused education, and self management protocols.
Dovepress

This journal is indexed on PubMed Central, MedLine and CAS. The manuscript management system is completely online and includes a very quick and fair peer-review system, which is all easy to use. Visit http://www.dovepress.com/testimonials.php to read real quotes from published authors. 